\title{
Behaviour of Temperate Phage Mu in Salmonella typhi
}

\author{
By M. SOBERON, $\dagger$ M. J. GAMA,$^{*} \ddagger$ J. RICHELLE $\ddagger$ AND J. MARTUSCELLI \\ Instituto de Investigaciones Biomédicas, Universidad Nacional Autónoma de México, \\ Apartado Postal 70228, DF 04510, México
}

(Received 26 March 1985; revised 12 August 1985)

\begin{abstract}
We have developed a convenient system for genetic analysis of Salmonella typhi exploiting the properties of the mutator phage Mu. In spite of the fact that wild-type Salmonella typhi strains do not allow $\mathrm{Mu}$ to form plaques on them, we have shown that these strains are actually sensitive to the phage. It proved possible to use $\mathrm{Mu}$ to induce mutations and to promote intra- and interspecific genetic transfer, without having to introduce the phage into the bacteria by means other than infection. Furthermore, we isolated Salmonella typhi derivatives on which $\mathrm{Mu}$ formed plaques, and studied the behaviour of $\mathrm{Mu}$ in these and wild-type strains.
\end{abstract}

\section{INTRODUCTION}

The Gram-negative enterobacterium Salmonella typhi is the causative agent of typhoid fever in humans. Different biological aspects of this bacterium have been investigated since its discovery; however, the genetics of the organism have not been systematically studied because a convenient system to manipulate its chromosome has not been developed. Phages are currently useful tools for the genetic study of bacteria. Among them, Mu appears particularly interesting, being a temperate phage that can insert its DNA randomly into the host genome and induce polar mutations at high frequency which are very stable and not leaky (Taylor, 1963; Martuscelli et al., 1971). Like other transposons, $\mathrm{Mu}$ induces various genetic rearrangements such as deletions, inversions, replicon fusions and transpositions of host DNA fragments (for review see Toussaint \& Résibois, 1983). Furthermore, $\mathrm{Mu}$ is a generalized transducing phage, even though the efficiency of transduction is not as good as that promoted by phage P1 (Howe, 1973; Howe \& Bade, 1975).

$\mathrm{Mu}$ host range is determined by the products of at least two pairs of phage genes, $\mathrm{S}$ and $\mathrm{U}, \mathrm{S}^{\prime}$ and $\mathrm{U}^{\prime}$, one set being silent while the other is expressed. Which pair is expressed depends on the orientation of the invertible $\mathrm{G}$ region of the phage genome (Van de Putte et al., 1980). Two phage types $\mathrm{G}(+)$ and $\mathrm{G}(-)$, recognize different cell surface receptors, which in both cases are located in the lipopolysaccharide (LPS) of the outer membrane of Gram-negative bacteria (Kamp \& Sandulache, 1983). Some bacteria, such as Escherichia coli K12 and 'Arizona hinshawii' are sensitive to $\mathrm{Mu}$ particles having the specificity corresponding to the $\mathrm{G}$ region in the + orientation, while others, such as Citrobacter freundii and Erwinia chrysanthemi are sensitive to phage particles having the specificity corresponding to the opposite $(-)$ orientation of the $G$ region (Van de Putte et al., 1980). Most bacterial species, including Salmonella typhimurium, are naturally resistant to phage Mu. However, Faelen et al. (1981) fortuitously found a $S$. typhimurium mutant on which Mu plaques. The mutation leading to sensitivity to Mu was shown to be linked to the his operon. Moreover, S. typhimurium strains with large deletions in the

† Present address: Centro sobre Fijación del Nitrógeno, Universidad Nacional Autónoma de México, Apartado Postal 565A, Cuernavaca, Morelos, México.

$\ddagger$ Present address : Laboratoire de Génétique, Université libre de Bruxelles, rue des Chevaux 67, 1640 Rhode-StGenèse, Belgium. 
Table 1. Bacterial strains and phages

\begin{tabular}{|c|c|c|}
\hline Strains & Characters & Source or reference \\
\hline \multicolumn{3}{|l|}{ E. coli } \\
\hline $\mathrm{C} 600$ & $\mathrm{Leu}^{-} \mathrm{Thr}^{-} \mathrm{Thi}^{-} \mathrm{Gal}^{-}$lac Y tonA supE & Appleyard (1954) \\
\hline C600(Mucts62) & As C600, lysogen with Mucts62 & This work \\
\hline MXR(Mucts62pApl) & $\begin{array}{l}\Delta(\text { pro-lac }) \text { galE Thi } \mathrm{Th}^{-} \text {rec } A 53, \text { lysogen for } \\
\text { Mucts62pApl }\end{array}$ & Faelen et al. (1978) \\
\hline $\begin{array}{l}\text { MXR(Mucts62pApl)/ } \\
\text { F Lac }^{\prime} \text { Pro-(Mu18Al) }^{-}(\mathrm{MuA}\end{array}$ & $\begin{array}{l}\text { As } \mathrm{MXR}(\mathrm{Mucts} 62 \mathrm{pApl}) \text { with } \mathrm{F}^{\prime} \mathrm{Lac}^{-} \mathrm{Pro}^{-} \\
\text {with } \mathrm{Mul} \text { (8) }\end{array}$ & Faelen et al. (1979) \\
\hline HB94 & $\mathrm{HfrH} \mathrm{Hsr}^{-} \mathrm{Gal}^{-}\left(\lambda c^{+}\right)$ & G. Alfaro, UNAM, Mexico \\
\hline \multicolumn{3}{|l|}{ S. typhimurium } \\
\hline MA766 & 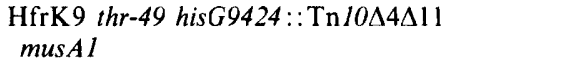 & Faelen et al. (1981) \\
\hline $\mathrm{ZJ} 1001$ & $\mathrm{Thr}^{+}$revertant of MA766 & This work \\
\hline \multicolumn{3}{|l|}{ S. typhi } \\
\hline JM1382 & $\begin{array}{l}\text { cym }^{\text {s }} \text { (requirement for cysteine or methionine) } \\
\text { Lac }^{-} \mathrm{Nal}^{\mathrm{R}}\end{array}$ & Martuscelli et al. (1971) \\
\hline $\mathrm{ZJ} 1$ & JM1382 hisG9424::Tn $10 \Delta 4 \Delta 11$ musAI & This work \\
\hline $\mathrm{ZJ} 2$ & $\mathrm{His}^{+}$spontaneous revertant of $\mathrm{ZJl}$ & This work \\
\hline ZJ11 & $\begin{array}{l}\text { His }^{+} \text {spontaneous revertant of JM1382 } \\
\text { hisG9424:: } \operatorname{Tn} 10 \Delta 4 \Delta 11\left(\mathrm{Mup}^{+}\right)\end{array}$ & This work \\
\hline MS22 & $\mathrm{ZJ} 2(\mathrm{Mucts} 62 \mathrm{pApl}) \mathrm{Ura}^{-}$ & This work \\
\hline \multicolumn{3}{|l|}{ Phages } \\
\hline Mucts62 & Thermoinducible & Howe (1973) \\
\hline Mucts62pApl & $\mathrm{Tn} 3$ in the $\mathrm{G}$ region & Leach \& Symonds (1979) \\
\hline Mul8Al & Mucts62pApl $\Delta(B-S)$ & Lefèbvre \& Toussaint (1981) \\
\hline Mucts62 mom 3452 & Mucts62 modification-deficient & Toussaint (1976) \\
\hline
\end{tabular}

his region are also able to support the growth of $\mathrm{Mu}$. From this observation and similar ones obtained with Klebsiella pneumoniae (Bachhuber et al., 1976) it has been proposed that sensitivity to $\mathrm{Mu}$ is due to the loss of a bacterial function.

It has also been observed that Mu can develop in a large number of hosts on which the phage can not adsorb, provided it is introduced into the cell by other means, such as on a broad hostrange conjugative plasmid like RP4 (Murooka et al., 1981). In this paper we report the use of phage $\mathrm{Mu}$ as a genetic tool to study $S$. typhi.

\section{METHODS}

Bacteria and phages. These are listed in Table 1.

Media. Bacteria and phages were grown in L broth (Miller, 1972). Mu lysates were titrated in L agar. Fry medium (Fry, 1959) was used to determine the sensitivity of the strains to phage Mu and to isolate Mu-bacterial lysogens. Minimal medium was M9 (Miller, 1972) with $0.2 \%(\mathrm{w} / \mathrm{v})$ glucose. When required, amino acids were added at a concentration of $40 \mu \mathrm{g} \mathrm{ml}^{-1}$ with the exception of glutamine, serine and proline, which were added at $150 \mu \mathrm{g} \mathrm{ml}^{-1}$. For growth of $S$. typhi, $\mathrm{Na}_{2} \mathrm{~S}_{2} \mathrm{O}_{3}$ was added to $\mathrm{M} 9$ at a concentration of $100 \mu \mathrm{g} \mathrm{ml}^{-1}$. The $\mathrm{Lac}^{-}$ phenotype was tested on MacConkey agar supplemented with $1 \%(\mathrm{w} / \mathrm{v})$ lactose.

Antibiotics were used at a concentration of $25 \mu \mathrm{g} \mathrm{ml}^{-1}$ for ampicillin (Amp) and nalidixic acid (Nal) and $100 \mu \mathrm{g} \mathrm{ml}^{-1}$ for tetracycline (Tet). Phages were diluted in SM buffer $(0 \cdot 01 \mathrm{M}$-Tris $/ \mathrm{HCl}, 0 \cdot 1 \mathrm{M}-\mathrm{NaCl}, 0 \cdot 02 \mathrm{M}$ $\mathrm{MgSO}_{4}, \mathrm{pH} 7.4$ ) and bacteria in $0.02 \mathrm{M}-\mathrm{MgSO}_{4}$.

Preparation of phage lysates. Phage lysates were prepared by heat induction of lysogens following the procedure described by Bukhari \& Ljungquist (1977).

$M u$ adsorption. Mu lysates were prepared by induction of a lysogen and the non-adsorbed phages were measured. Phages and bacteria were mixed at an m.o.i. of 3 for $15 \mathrm{~min}$ at $37^{\circ} \mathrm{C}$ and then the bacteria removed together with adsorbed phages by centrifugation. Phages remaining in the supernate were titrated.

Lysogenization by $\mathrm{Mu}$. A lawn of exponentially grown bacteria was spread on an $\mathrm{L}$ agar plate, and a drop of concentrated lysate of Mucts62pApl was spotted onto the lawn and incubated overnight at $32{ }^{\circ} \mathrm{C}$. Surviving bacteria isolated from the lysis area were then tested for $\mathrm{Amp}^{\mathrm{R}}$ and the presence of Mucts62 (i.e. immunity at $32^{\circ} \mathrm{C}$, and lysis and phage production at $42^{\circ} \mathrm{C}$ ).

Infection experiments. The procedure described by Bukhari \& Ljungquist (1977) was used.

Transduction experiments. These were done as described by Howe (1973).

Matings. These were done following the procedure of Miller (1972). 
RESULTS AND DISCUSSION

Sensitivity of S. typhi to $M u$

Our laboratory possesses an extensive collection of $S$. typhi strains isolated from patients of the 'La Raza' hospital, Mexico City. These strains are classified with respect to the surface Vi antigen (Anderson \& Williams, 1956). Many such clinical isolates of different Vi types were tested with $\mathrm{Mu}$ lysates prepared after induction of a lysogen. Such lysates contain a mixture of approximately $50 \%$ of particles with the host specificity corresponding to the $\mathrm{G}$ region in the + orientation and approximately $50 \%$ of particles with the host specificity corresponding to the opposite orientation of G (Van de Putte et al., 1980). None of the S. typhi strains tested allowed $\mathrm{Mu}$ to form plaques under the conditions described for Mu growth in E. coli K12 (Bukhari \& Ljungquist, 1977). However, $A m p^{R}$ bacteria were isolated after infection with Mucts62pApl, a Mu derivative which has part of its $\mathrm{G}$ region substituted by a portion of $\mathrm{Tn} 3$ (Leach \& Symonds, 1979). The analysis of these $A m p^{R}$ bacteria showed that they all contained a complete Mucts62pApl genome, since they produced infective particles after thermal induction. We concluded that Mu can infect $S$. typhi in spite of its inability to form plaques on this organism, and that $S$. typhi is sensitive to Mu particles with the specificity determined by the G region in the + orientation, because the phage used has the $G$ loop blocked in this orientation.

Following this observation we decided to isolate $S$. typhi strains on which Mu plaques (i.e. Mup $^{-}$strains) and study the development of $\mathrm{Mu}$ in wild-type strains $\left(\mathrm{Mup}^{+}\right.$).

\section{Isolation of $\mathrm{Mup}^{-}$strains}

S. typhimurium strains are naturally resistant to Mu infection, but Faelen et al. (1981) found a mutant on which Mu plaques. As the musAl mutation which leads to sensitivity is linked to the his operon, these authors labelled the his $G$ gene of the sensitive strain with $\operatorname{Tn} 10 \Delta 4 \Delta 11$, which can excise but not transpose. The mus $A l$ and $h i s G:: \operatorname{Tn} 10 \Delta 4 \Delta 11$ markers were introduced into an HfrK $9 S$. typhimurium so that both markers were transferred early by the donor strain during conjugation (Faelen et al., 1981).

$S$. typhi and $S$. typhimurium are closely related species and hybrid derivatives have been isolated (Diena et al., 1973). It was thus reasonable to expect to isolate Mup- strains of $S$. typhi by introducing the musAl character of $S$. typhimurium. In fact, previous experiments (L. Topisirovic, personal communication) showed that the musAl marker transferred into some Yugoslavian S. typhi strains was sufficient to allow $\mathrm{Mu}$ to form plaques on them. Therefore, we mated $\mathrm{Nal}^{\mathrm{R}}$ derivatives of $S$. typhi with MA766 for $30 \mathrm{~min}$ and selected the $\mathrm{Tet}^{\mathrm{R}} \mathrm{Nal}^{\mathrm{R}}$ colonies. These were obtained with frequencies ranging from $1.5 \times 10^{-6}$ to $3.5 \times 10^{-6}$. The analysis of these recombinants showed that all of them had the His ${ }^{-}$phenotype of the donor strain and that $70 \%$ allowed Mu to form plaques. The Mup ${ }^{-}$derivatives retained the Vi type of their $S$. typhi parent.

\section{Behaviour of $\mathrm{Mu}$ in $\mathrm{Mup}^{-}$and $\mathrm{Mup}^{+}$strains}

The ability of the different strains to adsorb phage $\mathrm{Mu}$ was determined as described in Methods. We found that $\mathrm{Mup}^{+}$and $\mathrm{Mup}^{-}$strains adsorbed phage Mu with the same efficiencies (see Table 2). This implied that the absence of phage plaques was not due to an insufficient adsorption of $\mathrm{Mu}$ on $S$. typhi $\mathrm{Mup}^{+}$membranes.

To measure the level of lysogenization, $S$. typhi was infected with the phage Mucts62pApl as described in Methods. We observed that $40 \%$ of the survivors of Mup- strains were lysogens, the actual frequency of lysogenization being $4.5 \times 10^{-4}$. It should be noted that the lysogenization frequency in the wild-type strains (Mup ${ }^{+}$) was $4 \times 10^{-5}$, i.e. 10-fold lower (Table 3). However, both Mup ${ }^{+}$and Mup- Mucts62pApl lysogens gave a burst of about $10^{9}$ infectious particles upon heat induction. This showed that the transposition level was equal in these strains, as transposition is the mechanism required for Mu replication during lytic growth.

As the efficiency of adsorption and the transposition frequency were the same in $\mathrm{Mup}^{+}$and Mup- strains, we determined whether the efficiency of Mu DNA injection was a limiting factor in $\mathrm{Mup}^{+}$as compared to Mup ${ }^{-}$strains. An experiment was designed that would enable distinction between phages actually propagated inside $S$. typhi and those that were carried by the 
Table 2. Effect of Mucts62 mom3452 development upon infection of S. typhi Mup ${ }^{+}$and Mup ${ }^{-}$ strains

Representative results of at least three determinations; variation in the results was 5 to $10 \%$.

JM1382 (Mup ${ }^{+}$) ZJ2 (Mup ${ }^{-}$)

No. of bacteria per $\mathrm{ml}$
Phage particles per $\mathrm{ml}$
Unadsorbed phages per $\mathrm{ml}$
Bacteria surviving infection
Infective centres titrated on:
E. coli $\mathrm{r}^{-} \mathrm{m}^{+}$
E. coli $\mathrm{r}^{+} \mathrm{m}^{+}$
Phage burst, 80 min after infection, titrated on:
E. coli $\mathrm{r}^{-} \mathrm{m}^{+}$
E. coli $\mathrm{r}^{+} \mathrm{m}^{+}$

$\begin{array}{ll}4.4 \times 10^{8} & 3.6 \times 10^{8} \\ 9.0 \times 10^{8} & 9.0 \times 10^{8} \\ 2.1 \times 10^{8} & 2.1 \times 10^{8} \\ 2.2 \times 10^{8} & 4.0 \times 10^{7} \\ 7.3 \times 10^{7} & 2.8 \times 10^{8} \\ 1.4 \times 10^{7} & 5.0 \times 10^{7} \\ 1.2 \times 10^{9} & 4.0 \times 10^{9} \\ 1.5 \times 10^{7} & 1.0 \times 10^{8}\end{array}$

Table 3. Lysogenization of S. typhi Mup ${ }^{+}$and Mup- strains by Mucts62pApl

Representative results of at least three determinations; variation in the results was 5 to $10 \%$.

\begin{tabular}{|c|c|}
\hline Infection by $\mathrm{Mu}$ & ts62pApl of \\
\hline JM1382 (Mup $\left.{ }^{+}\right)$ & $\mathrm{ZJ} 2\left(\mathrm{Mup}^{-}\right)$ \\
\hline$\frac{4.0 \times 10^{-5}}{3}$ & $\begin{array}{c}4.5 \times 10^{-4} \\
3\end{array}$ \\
\hline $1.0 \times 10^{9}$ & $9.5 \times 10^{8}$ \\
\hline
\end{tabular}

bacteria as non-adsorbed phages not removed by centrifugation. The fact that $S$. typhi does not possess an effective system to restrict DNA with $E$. coli K12- or $S$. typhimurium-specific modifications was exploited. This has been inferred from its ability to receive plasmids, such as $\mathrm{F}$ and resistance plasmids, during interspecific matings (G. Alfaro, personal communication), and the observation that the e.o.p. of phages Mu propagated in E. coli $\mathrm{K} 12$ or $S$. typhimurium is the same on $S$. typhi Mup ${ }^{-}$strains as on the original strain (data not shown). Furthermore, Mucts62 mom3452 (Toussaint, 1976), a phage deficient in its own DNA modification system and that is consequently more sensitive to host restriction, was used.

A Mucts62 mom3452 lysate was prepared by induction of an E. coli K12 lysogen and used to infect $S$. typhi Mup ${ }^{+}$and Mup ${ }^{-}$strains in parallel. Phages that actually infected $S$. typhi and propagated in it should no longer have the $E$. coli-specific DNA modification, while phages carried should retain it. Therefore, infective centres and phages produced upon infection were titrated on $E$. coli $\mathrm{K} 12$ restriction + and restriction - strains. The difference between the two bursts gives the number of phages that have lost $E$. coli $\mathrm{K} 12$ modification. The results (Table 2) show that the number of $S$. typhi infective centres was slightly but reproducibly lower (three- to four-fold) in the wild-type with respect to the Mup ${ }^{-}$strain. This difference was maintained at the level of phage bursts produced upon infection and at the level of bacteria surviving infection. This suggests that DNA injection is less effective in $\mathrm{Mup}^{+}$than in Mup ${ }^{-}$strains and could be an explanation for the absence of visible plaques in Mup ${ }^{+}$strains. Nevertheless, this defect is not necessarily the only one, since the difference in the efficiencies of lysogenization between the $\mathrm{Mup}^{+}$and Mup ${ }^{-}$strains (10-fold) seems too large to be completely explained by the difference in DNA injection efficiency.

\section{Isolation of auxotrophic strains}

One of the most distinctive features of $\mathrm{Mu}$ is its mutator property, which results from its random insertion into the host genome (Taylor, 1963, Martuscelli et al., 1971). This property was used to isolate auxotrophs of $S$. typhi. For this purpose, the Mup ${ }^{-}$strain $\mathrm{ZJ} 2$ was lysogenized with Mucts62 or Mucts62pAp1. The percentage of auxotrophs obtained ( 2 to $3 \%$ of lysogens) 
Table 4. Transduction between strains of S. typhi and between S. typhi and E. coli

Representative results of at least three determinations; variation in the results was 5 to $10 \%$. In both intraspecific and interspecific transduction the m.o.i. was 0.5 .

\begin{tabular}{|c|c|c|c|c|}
\hline Donor & Recipient & $\begin{array}{l}\text { Selective } \\
\text { marker }\end{array}$ & $\begin{array}{c}\text { Total } \\
\text { transduction } \\
\text { frequency }\end{array}$ & $\begin{array}{l}\text { Percentage } \\
\text { mini-Mu- } \\
\text { duction }\end{array}$ \\
\hline Mup $^{-}$ & $\begin{array}{c}\text { Intraspecific transduction } \\
\text { Mup }^{-}\end{array}$ & & & \\
\hline $\begin{array}{l}\text { ZJ1(Mucts62)/F' } \mathrm{Lac}^{-} \text {Pro }^{-} \\
(\text {Mu18A-1)[hisG }:: \operatorname{Tn} 10 \Delta 4 \Delta 11]\end{array}$ & $\mathrm{ZJ} 2\left[\mathrm{His}^{+}\right]$ & $\mathrm{Tc}^{\mathrm{R}}$ & $9 \cdot 0 \times 10^{-6}$ & 14 \\
\hline $\begin{array}{l}\mathrm{ZJ} 2\left(\text { Mucts62)/F' } \mathrm{Lac}^{-} \mathrm{Pro}^{-}\right. \\
(\mathrm{Mu} 18 \mathrm{~A}-1)\left[\mathrm{His}^{+}\right]\end{array}$ & $\mathrm{ZJ} 1[$ hisG:: $\operatorname{Tn} 10 \Delta 4 \Delta 11]$ & $\mathrm{His}^{+}$ & $8.5 \times 10^{-6}$ & - \\
\hline $\begin{array}{l}\text { 2. } \text { Mup }^{+} \\
\text {JM1382(Mucts62pAp1)/ } \\
\text { F Lac }^{\prime} \text { Pro }^{-}\left(\text {Mul8A-1) }\left[\text { Ura }^{+}\right]\right.\end{array}$ & $\begin{array}{c}\text { Mup }^{-} \\
\text {MS22 (Mucts62pApl) } \\
{\left[\mathrm{His}^{+} \text {Ura }^{-}\right]}\end{array}$ & Ura $^{+}$ & $1.0 \times 10^{-5}$ & - \\
\hline $\begin{array}{c}\text { Mup- } \\
\text { ZJ1(Mucts62)/F' } \text { Lac }^{-} \text {Pro }^{-} \\
(\text {Mu18A-1) }[\text { hisG }:: \operatorname{Tn} 10 \Delta 4 \Delta 11]\end{array}$ & $\underset{\mathrm{ZJ} 11\left[\mathrm{His}^{+}\right]}{\text {Mup }^{+}}$ & $T c^{R}$ & $1 \cdot 1 \times 10^{-6}$ & 14 \\
\hline S. typhi & $\begin{array}{c}\text { Interspecific transduction } \\
\text { E. coli }\end{array}$ & & & \\
\hline $\begin{array}{l}\mathrm{ZJ} 1(\text { Mucts62)/F'Lac } \\
\text { (Mul8A-1) }\end{array}$ & $\mathrm{C} 600$ & $\mathrm{Tc}^{\mathrm{R}}$ & $3.7 \times 10^{-7}$ & 90 \\
\hline
\end{tabular}

was the same as that observed in E. coli K12 (Howe, 1973); 26 of the auxotrophs were characterized and 11 different requirements were identified, suggesting that $\mathrm{Mu}$ can also insert into a large number of sites in S. typhi. The reversion frequency of these mutations was lower than $10^{-10}$, with the exception of two mutations for which reversion was around $10^{-8}$. For one of the mutants (MS22, $\mathrm{Ura}^{-}$), transduction of the wild-type allele resulted in the loss of the $\mathrm{Mu}$ prophage, showing that a $\mathrm{Mu}$ genome was closely linked to the mutated gene.

\section{Transduction}

Mu mediates generalized transduction at low frequency (Howe \& Bade, 1975). However, this frequency is 10 - to 100 -fold higher when mini-Mu/Mucts62 mixed lysates are used (Faelen et al., 1978, 1979). A mini-Mu is a phage with a large internal deletion and lacks the lytic and most of the morphogenetic functions. It can insert and transpose but is unable to accomplish a lytic cycle. However, in the presence of a helper phage such as Mucts62, the mini-Mu can be encapsidated with a piece of host DNA at one of its extremities. This is probably the reason for its increased transducing capacity. Moreover, a particular mechanism of transduction called mini-Muduction can also occur. Indeed, bacterial DNA flanked by two mini-Mu in the same orientation can be encapsidated by the helper phage. Upon infection of a sensitive bacterium, the mini-Mu/host DNA/mini-Mu sequence can insert at random into the bacterial chromosome using $\mathrm{Mu}$ transposase. The mini-Mu we used, Mu18A-1, carries the ampicillin resistance marker of.Mucts62pAp1. Strains carrying Mu18A-1 and Mucts62 were constructed by introducing an $\mathrm{F}^{\prime} \mathrm{Lac}^{-} \mathrm{Pro}^{-}(\mathrm{Mu} 18 \mathrm{~A}-1)$ episome into various $S$. typhi strains containing the Mucts62 prophage. The dilysogens were heat-induced and the mixed lysates obtained were used to transfer genetic material between different $S$. typhi strains as follows: (1) from Mup ${ }^{-}$to $\mathrm{Mup}^{-}$ strains; (2) from Mup ${ }^{+}$to Mup- strains; (3) from Mup- to Mup ${ }^{+}$strains (Table 4).

In the three situations analysed, the highest frequency of transduction was obtained at low m.o.i ( 0.5 to 1) (data not shown). When the recipient was a Mup ${ }^{-}$strain, whatever the mixed lysate used ( 1 and 2 , Table 4$)$, the transduction frequency was quite high $\left(\sim 10^{-5}\right)$ and comparable to that observed in E. coli K12 with the same system (Faelen et al., 1979). Consequently, there is a good probability of transducing any genetic marker of the $S$. typhi genome. Moreover, Tet $^{R}$ transductants were found that maintained the His ${ }^{+}$character of the recipient and acquired both $\mathrm{Mu}$ immunity and the ampicillin resistance marker (1, Table 4). These transductants were probably the result of mini-Muduction, since ampicillin resistance is a marker of Mul8A-1; these lysogens survive heat induction and do not produce phage particles. 
Furthermore the acquisition of Tet $^{\mathrm{R}}$ without loss of the His ${ }^{-}$phenotype means that there was no homologous recombination. In the case of genetic transfer from $\mathrm{Mup}^{+}$to $\mathrm{Mup}^{-}$strains (2, Table 4) it was not possible to test mini-Muduction because the recipient was a lysogenic strain. When the recipient was wild-type ( 3 , Table 4$)$, the frequency of transduction was lower. This can be related to a similar reduction (sevenfold) of the lysogenization frequency observed in these strains.

Mini-Muduction allows insertion of DNA without sequence homology. We tried to exploit this property for isolation of $S$. typhi-E. coli $\mathrm{K} 12$ hybrids, by transferring the his $G:: \operatorname{Tn} 10 \Delta 4 \Delta 11$ region from $\mathrm{ZJ} 1$ into $\mathrm{C} 600$. Experimental conditions were the same as for intraspecific transduction. The frequency of transduction was low but still reasonable (Table 4), given that the $E$. coli $\mathrm{K} 12$ strain used as recipient possessed an effective DNA restriction system. Almost all the transductants $(90 \%)$ seemed to be mini-Muductants, since in addition to the selected marker, $\mathrm{Tet}^{\mathrm{R}}$, they also received $\mathrm{Amp}^{\mathrm{R}}$ and $\mathrm{Mu}$ immunity; moreover, they retained the $\mathrm{His}^{+}$ allele of the recipient. Nevertheless, some true transductants were found. This can be explained by the partial homology, observed by DNA-DNA hybridization techniques, between the $S$. typhi and E. coli K12 genomes (Falkow et al., 1962).

It appears that $\mathrm{Mu}$ is a useful tool for the genetic analysis of $S$. typhi. Even though it can not plaque on wild-type strains, $\mathrm{Mu}$ can be used to induce mutations and promote intra- and interspecific genetic transfer. This opens many possibilities for the investigation of the virulence and pathogenicity of $S$. typhi. The isolation of strains on which $\mathrm{Mu}$ plaques also allows the analysis of other properties such as recombination, and DNA restriction and modification in this organism.

We gratefully thank M. Faelen and A. Toussaint for providing bacterial and phage strains and for stimulating discussions. We give special thanks to G. Alfaro for communicating unpublished results and to C. Gomez for stimulating discussions.

\section{REFERENCES}

Anderson, E. S. \& Williams, R. E. O. (1956). Bacteriophage typing of enteric pathogens and staphylococci and its use in epidemiology. Journal of Clinical Pathology 9, 94-127.

APPLEYARD, R. K. (1954). Segregation of $\lambda$ lysogenicity during bacterial recombination in $E$. coli $\mathrm{K} 12$. Genetics 39, 429-439.

BaChHUber, M., BRILl, J. W. \& Howe, M. (1976). Use of bacteriophage $\mathrm{Mu}$ to isolate deletions in the hisnif region of Klebsiella pneumoniae. Journal of Bacteriology 128, 749-753.

Bukhari, A. I. \& LJungquist, E. (1977). Bacteriophage Mu: methods for cultivation and use. In $D N A$ Insertion Elements, Plasmids and Episomes, pp. 749756. Edited by A. I. Bukhari, J. A. Shapiro \& S. L. Adhya. Cold Spring Harbor, NY: Cold Spring Harbor Laboratory.

Diena, B. B., Johnson, E. M., Baron, L., Wallace, R. \& Greenberg, L. (1973). Assay of typhoid vaccines with $S$. typhosa-S. typhimurium hybrids. Infection and Immunity 7, 5-16.

Faelen, M., Résibois, A. \& Toussaint, A. (1978). Mini-Mu: an insertion element derived from temperate phage Mu-1. Cold Spring Harbor Symposia on Quantitative Biology 43, 1169-1177.

Faelen, M., Toussaint, A. \& Résibois, A. (1979). Mini-Muduction: a new mode of gene transfer mediated by Mini-Mu. Molecular and General Genetics 176, 191-197.

Faelen, M., Mergeay, M., Geritz, J., Toussaint, A. \& LefÈbVRE, N. (1981). Genetic mapping of a mutation conferring sensitivity to bacteriophage $\mathrm{Mu}$ in Salmonella typhimurium LT2. Journal of Bacteriology 146, 914-919.

FalKow, S., Rownd, R. \& Baron, L. (1962). Genetic homology between $E$. coli $\mathrm{K} 12$ and Salmonella. Journal of Bacteriology 84, 1303-1311.

FRY, B. A. (1959). Conditions for the infection of $E$. coli with $\lambda$ phage and for establishment of lysogeny. Journal of General Microbiology 21, 676-684.

Howe, M. (1973). Transduction by bacteriophage Mu1. Virology 55, 103-117.

Howe, M. \& BADE, E. G. (1975). Molecular biology of bacteriophage Mu. Science 190, 624-632.

Kamp, D. \& Sandulache, R. (1983). Recognition of cell surface receptors is controlled by invertible DNA of phage Mu. FEMS Microbiology Letters 16, 131-135.

LEACH, D. \& Symonds, N. (1979). The isolation and characterization of a plaque forming derivative of bacteriophage $\mathrm{Mu}$ carrying a fragment of $\mathrm{Tn} 3$ conferring ampicillin resistance. Molecular and General Genetics 172, 179-184.

LefÈbVRE, N. \& Toussaint, A. (1981). Transfer of Salmonella typhimurium and Klebsiella pneumonia genes in E. coli $\mathrm{K} 12$ by mini-Muduction. Molecular and General Genetics 181, 268-272.

Martuscelli, J., Taylor, A. L., Cummings, D. J., Chapman, V., De Long, S. J. \& Cañedo, L. (1971). Electron microscopic evidence for linear insertion of bacteriophage $\mathrm{Mu}-1$ in lysogenic bacteria. Journal of Virology 8, 551-563. 
Miller, J. H. (1972). Experiments in Molecular Genetics. Cold Spring Harbor, NY: Cold Spring Harbor Laboratory

Murooka, Y., Takizawa, N. \& Harada, T. (1981). Introduction of bacteriophage $\mathrm{Mu}$ into bacteria of various genera and intergeneric gene transfer by RP4 : : Mu. Journal of Bacteriology 145, 358-368.

TAYLOR, A. L. (1963). Bacteriophage-induced mutations in Escherichia coli. Proceedings of the National Academy of Sciences of the United States of America 50, 1043-1051.
Toussaint, A. (1976). The DNA modification function of temperate phage $\mathrm{Mu}-1$. Virology 70, 17-27.

Toussaint, A. \& Résibois, A. (1983). Phage Mu: transposition as life-style. In Mobile Genetic Elements, pp. 105-158. Edited by J. A. Shapiro. New York: Academic Press.

Van de Putte, P., Cramer, S. \& Giphart-Gassler, M. (1980). Invertible DNA determines host specificity of bacteriophage Mu. Nature, London 286, 218 222. 